\title{
Title: \\ Galectins and their involvement in ocular disease and development
}

Authors: Joshua Luis ${ }^{a}$, Karen Eastlake ${ }^{a}$, Peng T Khaw ${ }^{a}$, G Astrid Limb ${ }^{a}$

a. National Institute for Health Research (NIHR) Biomedical Research Centre at Moorfields Eye Hospital NHS Foundation Trust and UCL Institute of Ophthalmology, London EC1V 9EL, United Kingdom

Corresponding author: Joshua Luis, email: Joshua.Luis@ucl.ac.uk 


\begin{abstract}
Galectins are carbohydrate binding proteins with high affinity to ß-galactoside containing glycoconjugates. Understanding of the functions of galectins has grown steadily over the past decade, as a result of substantial advancements in the field of glycobiology. Galectins have been shown to be versatile molecules that participate in a range of important biological systems, including inflammation, neovascularisation and fibrosis. These processes are of particular importance in ocular tissues, where a major theme of recent research has been to divert diseases away from pathways which result in loss of function into pathways of repair and regeneration. This review summarises our current understanding of galectins in the context important ocular diseases, followed by an update on current clinical studies and future directions.
\end{abstract}




\section{Introduction to Galectins}

Galectins (Gal) are carbohydrate binding proteins (CBP) with high affinity to ß-galactosides, which belong to the phylogenetically conserved family of lectins. To date, fifteen mammalian galectins have been discovered and named in the order of their discovery; of these, eleven have been identified in humans (Arthur et al., 2015). Galectins are widely distributed across different organisms, whilst significant variability exists in their expression between distinct species, tissues and subcellular compartments.

Understanding of the functions of galectins has grown steadily over the past decade. This has been made possible by substantial advancements in the field of glycobiology, which has resulted in a rapidly increasing number of galectin related publications. As a result, our understanding of carbohydrates has expanded beyond their traditional function as substrates of energy. Instead, we now recognise that carbohydrates, as well as their related molecules such as galectins, participate in much more complex systems which mediate intra- and inter-cellular signalling and regulation. This review outlines the chemical characteristics of galectins, their molecular interactions, and their role in systemic diseases. It then focuses on key ocular tissues and diseases followed by an update on current clinical studies and future directions.

\subsection{Chemical characteristics of galectins and their ligands}

Galectins can be broadly divided into three categories: prototypic, tandem repeat, and chimeric (Fig. 1). Prototypic galectins include Gal-1, -2 and -7 , which contain one carbohydrate recognition domain (CRD) and form homodimers upon binding to their glycoconjugates; tandem repeat galectins include Gal-4, $-8,-9$ and -12 , which contain two different CRDs; whilst Gal-3 is the only chimeric galectin capable of forming pentamers (Johannes et al., 2018). The distinctive structures of galectin molecules make them ideally suited for cross-linking glycans of either the same type, as in the case of homodimers and pentomers, or of different types, as in the case of tandem repeat galectins.

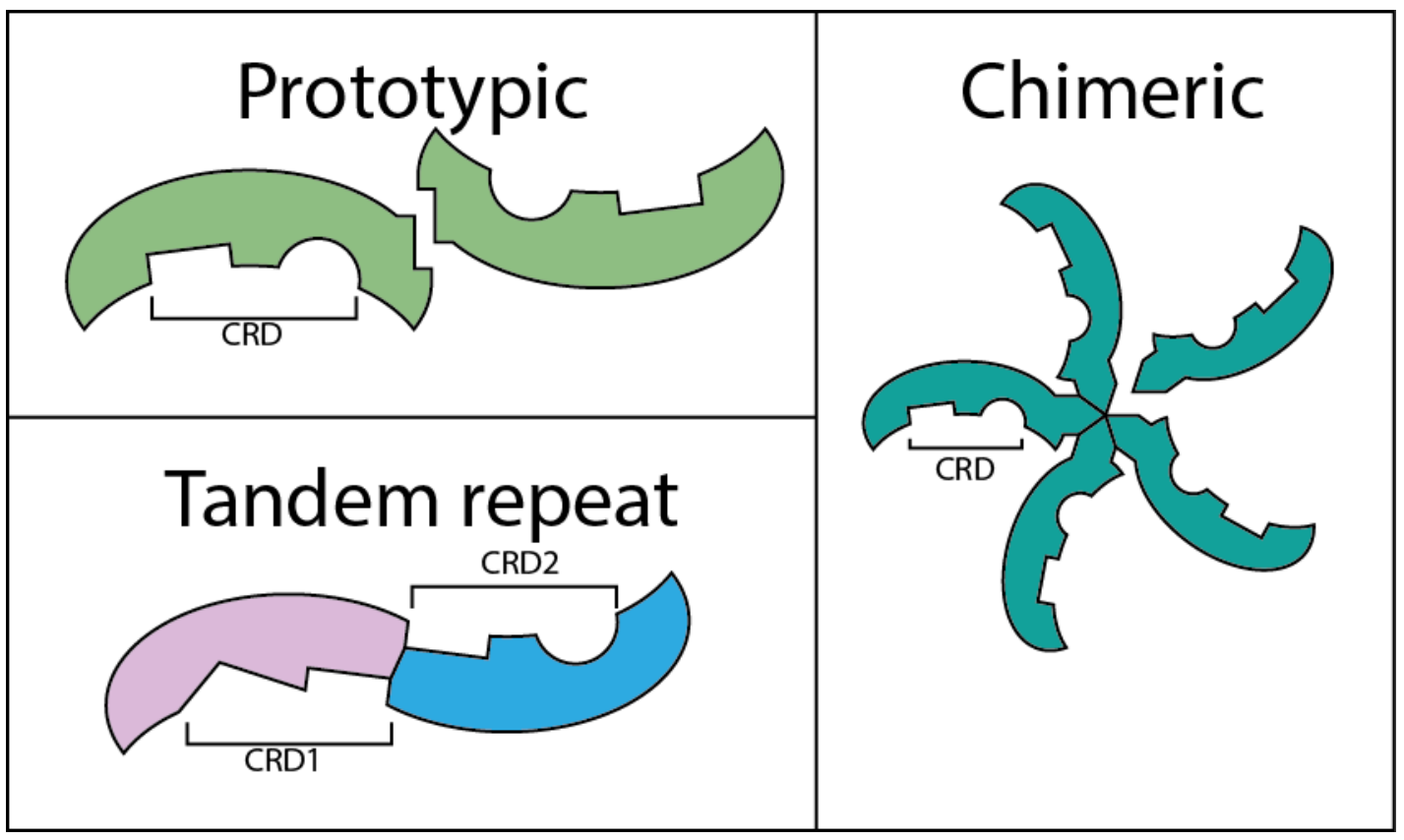

Figure 1. Classification of galectins. Galectins are divided into three subtypes: i) prototypic galectins contain a single CRD, and form homodimers, ii) tandem repeat galectins contain two distinct CRDs 
within the same molecule, and iii) chimeric galectins contain a single CRD but form pentomers. CRD, carbohydrate recognition domain.

Whilst Gal-1 and Gal-3 are widely distributed throughout the human body, other galectins appear to be more tissue specific (Cruzat et al., 2018). For instance, Gal-7 expression is restricted to stratified epithelia (Magnaldo et al., 1998), Gal-5 is specific to erythrocytes (Gitt et al., 1995), Gal-12 is found in adipocytes (Yang et al., 2011), and Gal-4 and -6 are primarily found in the gastrointestinal tract (Gitt et al., 1998). Gal-1, $-3,-7,-8$ and -9 have been found to be distributed within ocular tissues including the cornea, trabecular meshwork, lens, and retina (Fautsch et al., 2003; Gonen et al., 2000; Sugaya et al., 2015; Uehara et al., 2001). During states of ocular disease, the expression of these galectins and their corresponding glycoconjugates undergo significant changes. The impact of these changes as well as the mechanism governing them are addressed in later sections of this review.

Crucial to the function of galectins is the specific binding which occurs between their carbohydrate recognition domains (CRDs) and the corresponding glycans (Camby et al., 2006). The CRD regions of galectins are formed of a $\beta$-sheet sandwich structure which consists of two antiparallel $\beta$-sheets. Glycan binding occurs on the concave $\beta$-sheet surface, which can be further divided into five subregions named $A-E$; the central $C$ sub-region is specific for $B$-galactose, whilst the adjacent subregions correspond to sugars or functional groups attached to the ß-galactose residue (Fig. 2) (Chan et al., 2018; Nagae et al., 2009). This particular arrangement is crucial for carbohydrate binding and is responsible for the majority of molecular interactions between galectins and their binding targets.

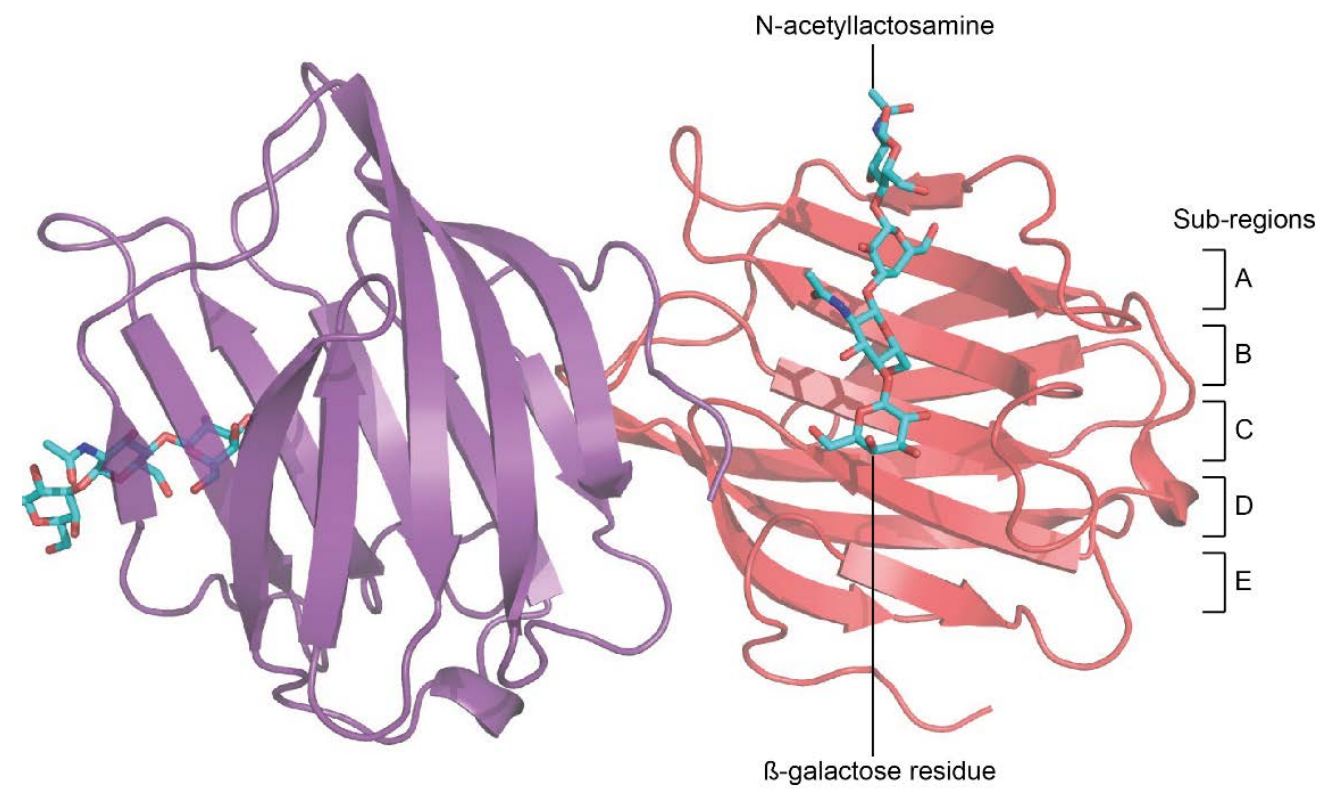

Figure 2. Prototypic Gal-9 dimer in complex with dimer. The $\mathrm{N}$-acetyllactosamine dimers are represented by ball-and-stick models; binding occurs on the concave $\beta$-sheet surface of Gal-9, where the terminal ß-galactose residue binds to the central C subregion. (Nagae et al., 2009)

Each galectin CRD recognises a specific region of a corresponding ß-galactose containing glycan, also known as the glycan determinant. Whilst a galectin CRD may be able to accommodate a large number of similar molecular structures, its affinity for a specific glycan determinant is orders of magnitude greater. The identification of glycan determinants specific to each CRD has proven to be an arduous undertaking, in part due to the multitudinous nature of glycans, which is further compounded by the lack of accessible and reliable carbohydrate sequencing techniques. 
Glycans are formed by the covalent attachment of monosaccharides and polysaccharides to organic molecules; this process is ubiquitous in nearly all known biological systems. The ability for CBPs to recognise and bind to their glycan determinant forms the foundation of the "sugar code" concept; which stipulates that information is stored and communicated through differential glycosylation states of a protein or lipid in addition to the underlying molecule itself (Gabius et al., 2004). As a result, many consider monosaccharides to be the third alphabet of life, alongside nucleotides and amino acids (Gabius, 2018). In order to achieve the intended interactions with galectins, corresponding glycan determinants must be encoded via appropriate glycosylation. For proteins, this is a post-translational modification process which takes place primarily in the Golgi apparatus. More specifically, O-glycosylation is carried out by the polypeptide-GalNAc-transferases (GALNT) enzyme family, whereas $\mathrm{N}$-glycosylation of mucins is carried out by the $\mathrm{N}$-acetylglucosaminyltransferase (MGAT) enzyme family (Boscher et al., 2011). Whilst galectins are able to bind to both Oglycosylated and $\mathrm{N}$-glycosylated proteins, high affinity binding generally requires $\mathrm{N}$-glycosylation; Gal-8 is an exception to this as it binds with high affinity to both types (Nielsen et al., 2018).

In contrast to proteins and nucleic acids which possess linear primary structures, monosaccharide units are able to form glycosidic linkages in several different positions. This allows glycans to take the form of complex branching chains. It has been estimated that a hexasaccharide has over $10^{12}$ theoretically possible configurations (Laine, 1994), with the number of functional glycan determinants estimated to be around 3000 (Cummings, 2009). Traditional pull-down experiments have identified a large number of potential molecules which interact with galectins, although the binding affinity for these molecules are not provided in these experiments (Kamili et al., 2016). More modern techniques using extensive glycan libraries have yielded better results, which have revealed a strong preference for the majority of galectin family members towards polylactosamine (polyLacNAc). Furthermore, specific polyLacNAc modifications also influence the strength of galectin binding, for example, $\alpha 2-6$ sialylation inhibits all galectin interactions except Gal-3, whereas $\alpha 2-3$ sialylation affects Gal-2, $-3,-4$ and -7 binding but has no impact on Gal-1 (Stowell et al., 2008).

To date, a number of interactors have been identified to possess the appropriate glycan determinants for various galectins. In general, these interactors are mainly localised in the extracellular matrix and cell membranes, as well as membranes found in intracellular structures such as exosomes, endosomes and lysosomes (Obermann et al., 2017). Galectins are secreted from cells via a non-classical pathway which remains incompletely understood (Popa et al., 2018); this is particularly important as the intracellular and extracellular functions of galectins appear to be distinct and are sometimes opposing (Johannes et al., 2018).

\subsection{Galectin functions and cellular activation pathways}

Human galectins are encoded by the lectin, galactoside-binding, soluble (LGALS) family of genes, the structures of these genes including their promoter regions have been well characterised (Chiariotti et al., 2002). A rapidly growing number of studies have demonstrated LGALS genes to be differentially expressed in a range of systemic and organ specific diseases, such as cancer, diabetes and inflammation. As galectins become established as disease biomarkers, there has been increasing interest in the molecular mechanisms governing their expression. Cytokines such as tumour necrosis factor alpha (TNF- $\alpha$ ), transforming growth factor beta (TGF- $\beta$ ) and the interleukin (IL) family are of particular interest, and recent studies have revealed their activity both upstream and downstream of galectins.

Galectins are the only CBPs in animals that can be found in both the intracellular and extracellular compartments (Leffler et al., 2002). Since proteins in the extracellular matrix (ECM) are richly 
glycosylated, glycans found on ECM proteins were some of the earliest galectin interactors to be identified (He and Baum, 2006). For instance, Gal-1 has been shown to interact with a number of ECM components including vitronectin, laminin and osteopontin to influence ECM assembly and turnover. At the same time, Gal-1 has also been shown to interact with cell-surface molecules including $\beta$-1 integrin (Moiseeva et al., 2003). These findings strongly suggest that Gal-1 serves a role in anchoring cell surface glycans to the ECM. Subsequent experiments have also demonstrated these interactions to have downstream effects on cell adhesion, migration, and proliferation. One of the key pathways involved in this process is the MAPK/ERK pathway, where not only does Gal-1 influence extracellular activation, but intracellular Gal-1 also appears to interact with proteins of the Ras family to further modulate cell growth and proliferation (Blazevits et al., 2016). In addition to the ECM, galectins have been shown to directly interact with surface glycans of circulating cells. Their effects on cells of the immune system have been particularly well studied, as detailed in later sections (Thiemann and Baum, 2016).

Amongst members of the galectin family, Gal-3 is unique in its capacity to self-associate into pentomers through its $\mathrm{N}$-terminal domain. This characteristic ability to crosslink multiple ligands is crucial for Gal-3 to perform its functions, many of which are thought to involve the stabilisation of cell surface receptors in order to modulate their function. Key examples of this include vascular endothelial growth factor (VEGF) and basic fibroblast growth factor (bFGF) signalling, where Gal-3 has pro-angiogenic effects dependent on both the activity of its CRD as well as its ability to oligomerise (Markowska et al., 2010). In addition, the FAK/PTK2 receptor also appears to be crucial in mediating the effect of Gal-3. Although the exact interplay between Gal-3, VEGF and focal adhesion kinase/protein tyrosine kinase 2 (FAK/PTK2) has not been fully elucidated, strong evidence exists to suggest that these pathways are closely related (Chen et al., 2012).

Another common theme for Gal-3 function is its association with lipid membranes. When found extracellularly, Gal-3 has been shown to facilitate phagocytosis of apoptotic cells; whilst intracellular Gal-3 tend accumulate around disrupted vesicular membranes and aid their clearance (Caberoy et al., 2012). Furthermore, in contrast to its extracellular function, intracellular Gal-3 appears to have anti- apoptotic properties in a pathway involving B-cell lymphoma 2 protein (Bcl-2) (Yang et al., 1996).

It was initially thought that the extracellular functions of galectins depended on their carbohydrate binding properties whereas their intracellular functions did not (Arthur et al., 2015). However, more recent studies have found notable exceptions to this generalisation. Nevertheless, the molecular insights of galectins underscore their versatility as they appear to take part in a diverse range of functions.

\section{Galectins in systemic diseases}

In contrast to other carbohydrate binding proteins which have relatively restricted functions, for instance selectins and toll-like receptors, galectins perform a number of different roles. To some extent, this complexity is a reflection of the varied functions of their ligand oligosaccharides, insofar as the ability to participate in seemingly unrelated intra- and inter-species biological interactions (Varki, 1993). One compelling theory at present proposes that the distinctive patterns of protein glycosylation expressed by different groups of cells form an important aspect of their microenvironment. Together with the production and secretion of a specific mixture of galectins into the extracellular milieu, these two factors act in concert to influence important processes including cell-ECM interactions, receptor-ligand signal modulation, and the trafficking of immune cells (Thiemann and Baum, 2016). 
Since its discovery as the most highly upregulated gene during heart failure, Gal-3 has emerged as a crucial molecule in the pathogenesis of cardiovascular disease (Sharma et al., 2004). In addition to becoming a promising biomarker for disease diagnosis and monitoring (Amin et al., 2017), the contribution of Gal-3 to disease progression has also been verified in a number of animal models. 29344292 (Suthahar et al., 2018). The presence of Gal-3 in cardiac diseases causes changes in cell cycle regulation, macrophage recruitment and fibroblast activation, which together result in cardiac remodelling and ultimately loss of cardiac function (Zhong et al., 2019).

Within several types of tumours, the expression of Gal-1, -3 and -9 has been associated with different clinical phenotypes (Bartolazzi, 2018). Whilst a higher concentration of Gal-1 has been shown to consistently correlate with more aggressive cancer progression, the roles of Gal-3 and Gal9 appear to be more variable (Camby et al., 2006). These effects have been shown to be mediated through alterations in cell proliferation and invasion (Inohara et al., 1998), tumour neovascularisation, as well as immunomodulation (Chou et al., 2018).

Interactions between galectins and the immune system were some of the first discoveries made in the exploration of their functions. This is in part due to the remarkable similarity between the antigen-antibody system and the specificity with which CBPs such as galectins bind to their corresponding glycan determinants. Indeed, Gal-3 was initially named Mac-2 as it was found in macrophages at high concentrations (Lakshminarayan et al., 2014). Gal-3 has predominantly been associated with detrimental effects during inflammation; for instance, serum concentrations of Gal-3 and Gal-3 binding protein (G3BP) are increased in patients with Behçet's disease (Lee et al., 2007), although more recent data suggest that the upregulation of Gal-3 may be playing a protective role (Lee et al., 2019). Other galectins such as Gal-2, -9 and -10 also participate in the regulation of T cells and their associated cytokines, as reviewed in detail elsewhere (Arthur et al., 2015).

Gal-1 has been shown to have potent immunosuppressive functions via multiple mechanisms of action. Firstly, Gal-1 is an established inducer of T cell apoptosis (Perillo et al., 1995); secondly, Gal-1 plays an important role during normal development and maturation of T cells, including regulatory $T$ cells via the upregulation of FOXP3 (Juszczynski et al., 2007; van der Leij et al., 2004); and lastly, Gal1 has been shown to induce IL-10 production and to inhibit IFN- $\gamma$ production in both CD4+ and CD8+ T cells (Perillo et al., 1995). These effects were particularly evident in tumours, which suggests that elevated Gal-1 concentrations contribute to neoplasm related immunosuppression.

Tissue fibrosis is a common converging pathway for a number of disease process following injury, characterised by accumulation of ECM, tissue contraction and loss of function. It has recently emerged that Gal-3 is a central regulator of fibrosis, as evidenced by studies in the lung, kidney, and liver (Li et al., 2014). The pathogenesis of pulmonary fibrosis has been investigated in particular detail, where Gal-3 was found to regulate TGF- $\beta$, reduce phosphorylation and nuclear translocation of $\beta$-catenin but had no effect on Smad2/3 phosphorylation (Nishi et al., 2007). Research in idiopathic pulmonary fibrosis has also demonstrated the ability for Gal-3 to induce epithelial mesenchymal transition and myofibroblast activation via TGF- $\beta 1$ (Mackinnon et al., 2012), with later studies demonstrating similar results in atrial fibrosis (Shen et al., 2018). These findings are further substantiated by animal models of Gal-3 downregulation which attenuate tissue fibrosis, in a process accompanied by a decrease in TGF- $\beta$ and alphas smooth muscle actin ( $\alpha$-SMA) expression (Henderson et al., 2006). One hypothesis for this observation is that the crosslinking effect of Gal-3 on $\mathrm{N}$-glycosylated TGF $\beta$ receptors via Mgat 5 activity may stabilise and potentiate TGF- $\beta$ signalling (Partridge et al., 2004). 
The ophthalmic field has made significant contributions to our understanding of galectins as a whole; the exquisitely organised structures of the eye renders it an ideal organ to further investigate these molecules. The following sections explore our current knowledge on the involvement of galectins in ocular diseases (Table 1, Fig.3), it is worth keeping in mind that much of the research in this field can potentially be translated to other organs.

\begin{tabular}{|c|c|c|c|}
\hline & Molecule & Effects & References \\
\hline \multirow[t]{6}{*}{ Cornea } & Gal-1 & $\begin{array}{l}\text { Reduce inflammatory response in } \\
\text { Pseudomonas aeruginosa infections }\end{array}$ & (Suryawanshi et al., 2013) \\
\hline & Gal-3 & Anchors Mucins -1 and -16 & (Argueso et al., 2009) \\
\hline & & $\begin{array}{l}\text { Promotes cell migration and wound } \\
\text { healing }\end{array}$ & $\begin{array}{l}\text { (Cao et al., 2002a; } \\
\text { Saravanan et al., 2009) }\end{array}$ \\
\hline & & Reduced in dry eye diseases & (Soria et al., 2018) \\
\hline & & $\begin{array}{l}\text { Increased in inflammatory corneal } \\
\text { diseases }\end{array}$ & $\begin{array}{l}\text { (Hrdlickova-Cela et al., } \\
\text { 2001) }\end{array}$ \\
\hline & Gal-7 & Promotes re-epithelialisation & (Cao et al., 2002a) \\
\hline \multirow[t]{4}{*}{ Glaucoma } & Gal-3 & Upregulated in the $\mathrm{TM}$ and $\mathrm{ONH}$ & $\begin{array}{l}\text { (Belmares et al., 2018; } \\
\text { Fautsch et al., 2003) }\end{array}$ \\
\hline & & $\begin{array}{l}\text { Present in higher concentrations in the } \\
\text { aqueous humour }\end{array}$ & (Tripathi et al., 1994) \\
\hline & & Promotes RGC loss & (Abreu et al., 2017) \\
\hline & Gal-3 & Anchors cells within the TM & (Diskin et al., 2009) \\
\hline \multirow{8}{*}{$\begin{array}{l}\text { Ocular } \\
\text { immunology }\end{array}$} & Gal-1 & Contributes to ocular immune privilege & (Ishida et al., 2003) \\
\hline & & Ameliorates EAU & (Toscano et al., 2006) \\
\hline & & Downregulates IL-1b, -16 and MCP-1 & (Romero et al., 2006) \\
\hline & Gal-3 & Causes microglial inflammation & (Burguillos et al., 2015) \\
\hline & & Enhances phagocytosis & (Karlsson et al., 2009) \\
\hline & Gal-8 & Ameliorates EAU & (Sampson et al., 2015) \\
\hline & & $\begin{array}{l}\text { Increases the number of regulatory } T \\
\text { cells }\end{array}$ & (Sampson et al., 2016) \\
\hline & Gal-9 & Contributes to ocular immune privilege & $\begin{array}{l}\text { (Shimmura-Tomita et al., } \\
\text { 2013) }\end{array}$ \\
\hline \multirow{5}{*}{$\begin{array}{l}\text { Neovascular } \\
\text { diseases }\end{array}$} & Gal-1 & Activates VEGFR2 & (Markowska et al., 2010) \\
\hline & & Promotes choroidal neovascularisation & (Wu et al., 2019) \\
\hline & & $\begin{array}{l}\text { Upregulated in proliferative diabetic } \\
\text { retinopathy }\end{array}$ & \\
\hline & Gal-3 & Activates and stabilises VEGFR2 & (Markowska et al., 2011) \\
\hline & Gal-8 & Promotes lymphangiogenesis & (Chen et al., 2016) \\
\hline \multirow{2}{*}{$\begin{array}{l}\text { Epithelial } \\
\text { mesenchymal } \\
\text { transformation }\end{array}$} & Gal-1 & $\begin{array}{l}\text { Mediates adhesion of the photoreceptor } \\
\text { layer to the interphotoreceptor matrix }\end{array}$ & (Uehara et al., 2001) \\
\hline & & $\begin{array}{l}\text { Over-expression correlates with RPE } \\
\text { differentiation and migration }\end{array}$ & $\begin{array}{l}\text { (Alge et al., 2006; Eastlake } \\
\text { et al., 2018) }\end{array}$ \\
\hline
\end{tabular}




\begin{tabular}{|l|l|l|l|}
\hline & Gal-3 & $\begin{array}{l}\text { Causes clustering of CD147 and intergrin- } \\
\beta 1\end{array}$ & (Priglinger et al., 2013) \\
\hline
\end{tabular}

Table 1. Functions of galectins in ocular diseases. EAU, experimental autoimmune uveitis; IL, interleukin; MCP, monocyte chemotactic protein; ONH, optic nerve head; RGC, retinal ganglion cell; RPE, retinal pigmented epithelium; TM, trabecular meshwork; VEGFR, vascular endothelial growth factor receptor

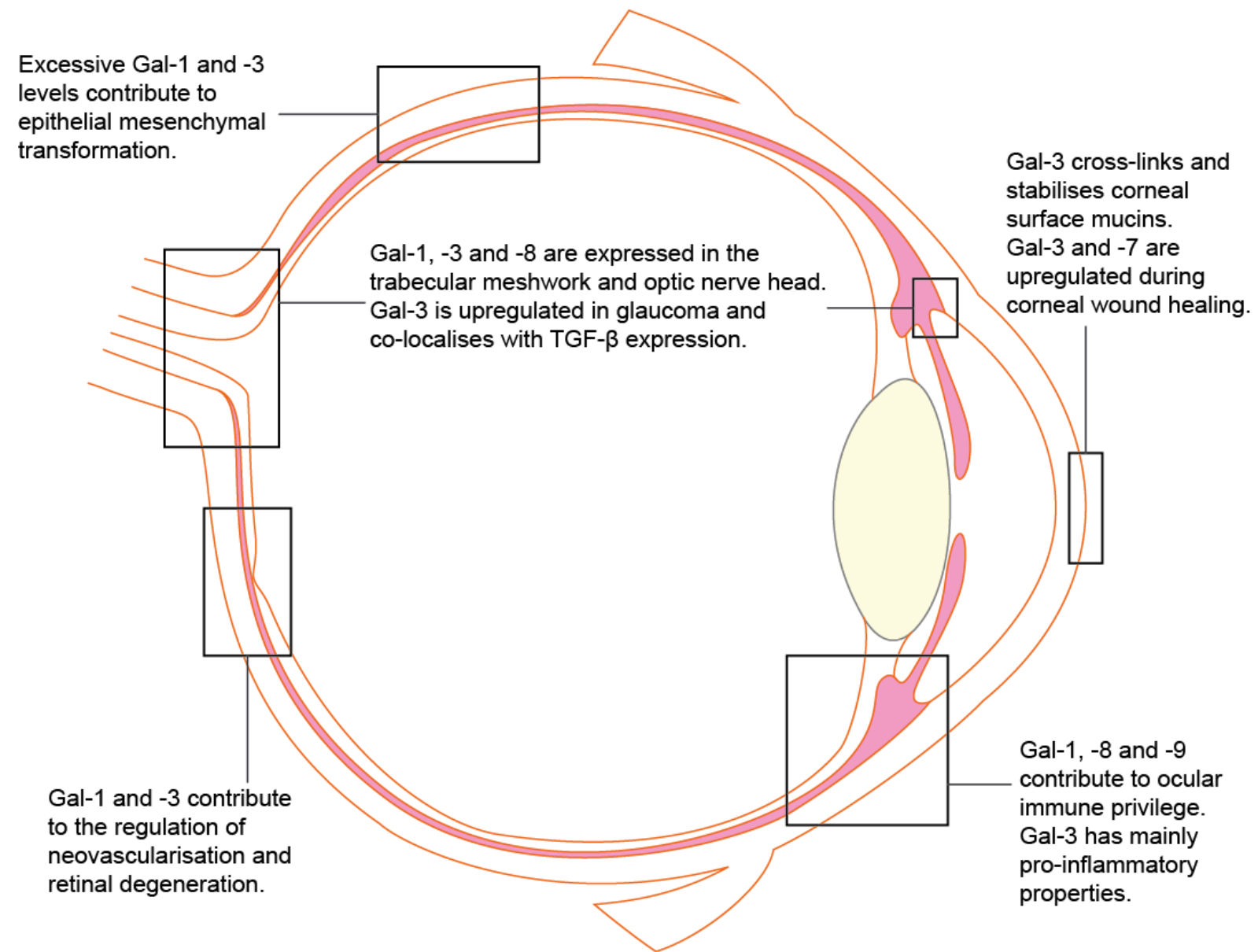

Figure 3. Roles of galectins within the eye. Schematic diagram showing the main known roles of galectins within the different cellular structures of the eye.

\section{Involvement of galectins in corneal disease}

A major role of Gal-3 in the cornea relates to its interactions with the glycocalyx, a layer of large glycoproteins covering the apical surface of the corneal epithelium, composed mainly of mucins. Gal3 associates closely with Mucins -1 and -16 , which anchors these proteins to the underlying epithelial cells and each other (Argueso et al., 2009; Uchino, 2018). The glycocalyx has hydrophilic properties and serves several important functions, including mechanical impairment of pathogens, tear film stabilisation, and lubrication during blinking.

The extracellular domains of mucins can extend up to 500nm from the plasma membrane and are highly glycosylated; in fact, the carbohydrate content of mucins can account for over $70 \%$ of their molecular weight in some cases (Taniguchi et al., 2017). Due to the high proportion of serine and threonine residues in these molecules, the majority of carbohydrate conjugates in mucins are O- 
glycans whereas relatively few N-glycans are present. Both O-glycans and $\mathrm{N}$-glycans have been demonstrated to bind to Gal-3, and the interactions between mucins and Gal-3 is critical in the overall integrity of the glycocalyx (Argueso et al., 2009; Guzman-Aranguez and Argueso, 2010). The ability for Gal-3 to stabilise ocular surface mucins is largely attributed to its ability to self-associate to both the $\mathrm{C}$ - and $\mathrm{N}$-terminal domains which facilitates the formation of large complexes (Ahmad et al., 2004; Argueso, 2013). Studies which inhibited MGAT1 function led to impaired stability of surface MUC16 and weakening of the glycocalyx (Taniguchi et al., 2017). This effect was shown to be mediated through modulation of the interaction between MUC16 and Gal-3, and to increased stress in the endoplasmic reticulum leading to unfolded protein response.

In addition to mucins, a number of other binding partners have been identified for Gal-3. CD147 (also known as EMMPrin and basigin) is a particularly important molecule found to co-localise with Gal-3 in areas of ulceration and gelatinolytic activity in human cornea tissue (Cruzat et al., 2018). Gal-3 appears to cause clustering of CD147 to initiate cell-cell detachment and induces matrix metalloproteinases (Mauris et al., 2014). Additionally, Gal-3 has also been shown to bind selectively to clusterin, another important molecule in the maintenance of ocular surface integrity (Fini et al., 2016). Gal-3 has also been demonstrated to promote cell migration and wound healing, via $\alpha 3 \beta 1$ integrin and activation of focal adhesion kinase and Rac1 GTPase (Saravanan et al., 2009).

Clinical studies have demonstrated that Gal-3 expression is reduced in the conjunctival epithelium of patients with dry eye disease and meibomian gland dysfunction (Soria et al., 2018). Conversely, Gal3 protein levels are increased in the tears of patients with ocular inflammatory conditions such as sarcoidosis and adenoviral conjunctivitis, but not in healthy subjects or those with non-inflammatory conditions such as corneal degeneration (Hrdlickova-Cela et al., 2001). Taken together, these findings suggest that Gal-3 is an integral part of the milieu of extracellular molecules found in the corneal epithelium; and that its presence is important for the maintenance of a healthy ocular surface. However, it remains unclear whether elevated Gal-3 concentrations within the tear film has a pathogenic role in inflammatory conditions, or whether it is simply a reflection of the presence of inflammatory cells such as macrophages, which are known to express Gal-3 abundantly.

Additional evidence shows that Gal-3 may be exploited as a binding partner by Herpes Simplex Virus type 1 (HSV-1), as part of the initial HSV-1-glycocalyx interaction necessary for the intracellular translocation of HSV-1 (Woodward et al., 2013). In this context, it has been demonstrated that the interaction between Gal-3 and HSV-1 is dramatically reduced within an intact glycocalyx where the majority of Gal-3 is already bound to mucins. This may help to explain the propensity for HSV-1 to cause corneal infection following epithelial injury, as the healing edge of areas of corneal wound exhibit increased concentration of Gal-3 molecules. In the context of Pseudomonas aeruginosa corneal infections, Gal-1 treatment has been shown to reduce the pro-inflammatory Th17 cell response, whilst promoting the activities of Th2 and IL-10 (Suryawanshi et al., 2013). Further characterisation of the role of galectins in other forms of infective keratitis would contribute to our understanding of the role of galectins in corneal infection and inflammation.

Gal-7 is known to play an important role in promoting cell-ECM interactions, as evidenced by microarray cDNA sequencing in a model of corneal excimer laser injury, which revealed significant upregulation of this molecule during wound healing (Cao et al., 2002b). Enhanced expression of Gal7 was confirmed by subsequent experiments, which also found that Gal-8 and -9 are upregulated following corneal cauterisation (Chen et al., 2015). Further studies in mouse models of corneal reepithelialisation have found that Gal-3 is concentrated in areas of migrating epithelium, whereas Gal-7 is upregulated throughout the epithelium (Cao et al., 2003). In addition, Gal-3/- mice have shown significantly lower wound closure rates than wild type animals, whereas Gal-1/- mice did not 
show such effect. Interestingly, the application of exogenous Gal-7 but not of Gal-3 was able to stimulate corneal re-epithelialisation in Gal-3\% mice (Cao et al., 2002a). In this case, the fact that exogenous Gal-3 did not have a rescue effect on $\mathrm{Gal}_{-1 /-}$ mice raises the possibility that Gal-3 must be present intracellularly to contribute significantly to normal wound healing.

\section{Galectins and glaucoma}

Glaucoma is a heterogeneous group of disorders which share the hallmark features of retinal ganglion cell (RGC) loss and optic nerve head (ONH) remodelling. In most forms of glaucoma, increased intraocular pressure is the prominent aetiological factor, and remains the only modifiable risk factor targeted in clinical practice (Weinreb et al., 2014). The molecular processes which occur in the trabecular meshwork (TM) and ONH remodelling as well as RGC cell degeneration remain incompletely understood and constitute major areas of current glaucoma research. Galectins, in particular Gal-3, has been implicated in both of these pathogenic processes.

The rate at which aqueous fluid drains out of the anterior chamber is regulated by cells of the TM and their modifications of the surrounding extracellular matrix. TGF- $\beta 2$ has been demonstrated to be an important factor involved in TM fibrosis (Kang et al., 2013), as evidenced by elevated concentrations of this cytokine in the aqueous humour of patients with primary open angle glaucoma (Tripathi et al., 1994). Concurrently, there is evidence of Gal-3 upregulation in the TM and the ONH of human glaucomatous eyes (Belmares et al., 2018; Fautsch et al., 2003), and given the known significance of Gal-3 involvement in fibrogenic states of other organs (Suthahar et al., 2018), it would be invaluable to elucidate the interaction between Gal-3 and TGF- $\beta$ in the context of glaucoma.

One potential explanation for the upregulation of Gal-3 in glaucoma is through its interactions with matricellular proteins, as suggested by in vitro studies showing that inhibition of Gal-3 in sarcoma cells promotes their adhesion and migration on laminin 111, a process that is dependent on the activation of the PI-3 kinase dependent pathway (Melo et al., 2011). TGF- $\beta 2$ also positively regulates matricellular protein activity; in the TM, it is well-documented that TGF- $\beta 2$ signalling activates $p 38$ and Smad 2/3 pathways to regulate the production of a number of important matricellular proteins including SPARC (Rhee et al., 2003), thrombospondins- 1 and -2 , tenascins- $\mathrm{C}$ and $-\mathrm{X}$, and osteopontin (Chatterjee et al., 2014; Rhee et al., 2009). The accumulation of Gal-3 and various matricellular proteins could lead to significant ECM remodelling and therefore increased TM outflow resistance as observed in primary open angle glaucoma (Melo et al., 2011).

Gal-1 and -8 have been found throughout the human trabecular meshwork and Schlemm's canal (Fautsch et al., 2003). In vitro, TM cells strongly adhered to Gal-8 coated wells, but not to Gal-1 or Gal- 3 coated wells. This is thought to be mediated by the binding between Gal- 8 and $\beta 1$ integrins present on TM cell membranes; and more specifically, the CRD region of Gal-8 appears to be selective for the 3-sialylated glycans contained within $\beta 1$ integrins (Diskin et al., 2009).

In addition to its potential role in fibrosis, Gal-3 has also been implicated in the pathogenesis of glaucomatous RGC loss. This is illustrated by findings that Gal-3 knockout mice exhibit higher rate of RGC survival following optic nerve crush injury (Abreu et al., 2017). Furthermore, electron microscopy analysis of degenerating RGCs shows increased cellular fragmentation in Gal-3-/- mice, which suggests that there is incomplete clearance of damaged RGCs (Abreu et al., 2017). The current hypothesis for this effect is attributed to Gal-3 mediated microglia activation, substantiated by existing evidence in the central nervous system (CNS) that Gal-3 dependent microglial activation results in inflammatory neurodegeneration (Siew et al., 2019). 


\section{Role of galectins in immune mediated eye disease}

In its normal state, the intraocular microenvironment is a well-established site of immune privilege. The immunosuppressive effects are achieved through a combination of synergistic mechanisms including the blood-retinal barrier and locally released molecules (Mochizuki et al., 2013). There is accumulating evidence that Gal-1 is one such molecule which contributes to this effect, in accord with its immunomodulatory functions elucidated in other organs. Within the retina, the role of Gal-1 was further confirmed by experiments using retinal pigmented epithelial cells from Gal-1/- mice which exhibited significantly dampened immunosuppressive properties (Ishida et al., 2003). In addition to inducing T-cell apoptosis, Gal-1 has also been shown to deactivate microglia in the CNS, which has downstream effects of decreasing the production of important pro-inflammatory cytokines such as TNF- $\alpha$ and monocyte chemotactic protein-1 (MCP-1) (Starossom et al., 2012). It is of interest to note that the immunosuppressive properties exhibited by Gal-1 appear to require cellcell contact and do not occur over longer distances (Fajka-Boja et al., 2016).

During experimental autoimmune uveitis, recombinant Gal-1 ( $\mathrm{rGal}-1$ ) has been shown to ameliorate inflammation, via diversion of the Th1 pre-dominant response towards Th2 and Treg mediated antiinflammatory state (Toscano et al., 2006). This finding was further validated using a rodent model of endotoxin-induced uveitis, where rGal-1 had a similar anti-inflammatory effect. This was reflected in the downregulation of cytokines present in ocular tissue and included IL-1b, IL-6 and MCP-1. (Zanon Cde et al., 2015) Interestingly, anti-Gal-1 antibodies have been found in patients with autoimmune and toxoplasmic retinochoroiditis, which correlated with disease progression (Romero et al., 2006).

Another galectin which has been shown to have immunoregulatory effects within the eye is Gal-8. Using a murine model of experimental autoimmune uveitis, intraperitoneal treatment with exogenous Gal-8 has been shown to increase the number of regulatory T cells, as well as increase their CTLA-4 and IL-10 expression. This is accompanied by a decrease in the production of T-helper 1 (TH1) and TH17 cells (Sampson et al., 2015). These immunomodulatory effects were later confirmed in vitro; where Gal-8 stimulated Treg conversion occurred via the binding of Gal-8 to TGF- $\beta$ and IL-2 receptors which led to downstream activation of Smad3 and STAT5 signalling (Sampson et al., 2016).

In addition to Gal-1 and Gal-8, Gal-9 has also been shown to be a molecule which contributes to the immune privileged status of the eye as well. Gal-9 is constitutively expressed in a number of ocular tissues, including the corneal epithelium, corneal endothelium and iris-ciliary body (ShimmuraTomita et al., 2013). The immunosuppressive properties of Gal-9 has been attributed to its binding to T-cell immunoglobulin and mucin domain (Tim)-3 receptor, leading to apoptosis of effector T-cells but not regulatory T-cells (Sehrawat et al., 2009). In support of these findings, the expression of Gal9 was found to be significantly lower in corneal tissue obtained following graft rejection as compared to successful grafts; and the blockade of Gal-9 increased corneal graft destruction in mice (Sugaya et al., 2015). This effect was also seen in animal models of allergic conjunctivitis, where Gal9 blockade resulted in an increase in severity (Fukushima et al., 2008). Furthermore, in the context of Thyroid-associated ophthalmopathy, the interaction between Gal-9 and Tim3 caused downstream suppression of the Akt/NF-kB pathway, resulting in an inhibitory effect on TLR mediated inflammation which also shares Akt/NF-kB signalling (Luo et al., 2017).

In contrast to the anti-inflammatory properties of Galectins mentioned above, Gal-3 has predominantly shown pro-inflammatory functions. Endogenous Gal-3 from microglia appears to act as a ligand for toll-like receptor 4 (TLR4), which contributes to microglial inflammation and subsequent detrimental effects (Burguillos et al., 2015); binding of Gal-3 to TLR4 is dependent of the CRD region of Gal-3, which then increases Gal-3 self-association. These findings are comparable to a 
study of Huntington's disease, where both human and mouse subjects with the disease exhibited higher concentrations of Gal-3 in the brain and plasma, which was found to be microglia driven and occurred before any clinically measurable motor impairment (Siew et al., 2019). The upregulation of Gal-3 in CNS microglia appeared to be nuclear factor kappa B (NFkB) mediated, whilst the downstream pro-inflammatory effects were driven by intracellular but not extracellular Gal-3. Increased intracellular Gal-3 was localised to areas of lysosomal damage and resulted in pyrin domain-containing 3 (NLRP3) inflammasome activation and upregulation of IL-1 $\beta$ (Uchino et al., 2018). Furthermore, Gal-3 exhibits opsonin properties to enhance phagocytosis and aid clearance (Karlsson et al., 2009). Although the immunological role of Gal-3 in the retina is less well understood in comparison to the CNS, there is increasing evidence that some of the detrimental mechanisms are shared. As such, Gal-3 is likely to significantly contribute to the pathogenesis of ocular inflammatory conditions (Karlsson et al., 2009).

\section{Galectins and ocular neovascularisation}

Over the last few decades, VEGF has emerged as a key regulator of blood vessel formation, particularly in the context of tumorigenesis and ocular diseases (Ferrara and Adamis, 2016). Blocking the actions of VEGF within the eye has dramatically shifted our approach to controlling the clinical consequences of pathological neovascularisation in diseases such as diabetic retinopathy, age related macular degeneration and retinal vein occlusion.

In more recent years, Galectins -1 and -3 have been noted to interact with VEGF signalling and modify its effects; in particular, Gal-3 appears to stabilise VEGFR2 on the plasma membrane and prevent its internalisation (Markowska et al., 2011). Both Gal-1 and Gal-3 increase the proliferation and capillary tube formation of human endothelial cells, Gal-1 and Gal-3 individually activate VEGFR2 (Markowska et al., 2010), whereas the combination of these two galectins leads to VEGFR1 activation (D'Haene et al., 2013). Upregulation of Gal-1 has also been observed in a mouse model of laser induced choroidal neovascularisation (CNV). It is of interest that deletion of the LGALS1 gene in this model suppressed VEGFR2 expression and attenuated CNV formation, fibrosis and markers of epithelial-to-mesenchymal transition (EMT) (Wu et al., 2019). Gal-1 inhibition by specific inhibitors has also shown to attenuate of retinal angiogenesis in animal models of retinal neovascularisation (Wu et al., 2019; Yang et al., 2017).

Whilst both Gal-1 and -3 increase the proliferation and capillary tube formation of human vascular endothelial cells resulting in new blood vessels formation (Markowska et al., 2010; Ridano et al., 2017), Gal-8 has been shown to act specifically on human lymphatic endothelial cells and promotes lymphangiogenesis in a pathway involving integrin VEGF-C, and podoplanin. 27066737 (Chen et al., 2016)In diabetic retinopathy, both IL-1 $\beta$ and Gal-1 are upregulated following stimulation by advanced glycation endproducts (AGE) via the activation of toll-like receptor (TLR) 4 signalling (Kanda et al., 2017), whilst expression of Gal-1 is downregulated by the glucocorticoid receptor via dual specificity phosphatase (DUSP) 1 (Hirose et al., 2019). A recent study of epiretinal membranes from patients with PDR also confirmed Gal-1 to be upregulated, in correlation with VEGF expression and microvessel density (Abu El-Asrar et al., 2020). Vitreous samples from patients with PDR also showed increased Gal-1 expression, although this was not found to be correlated with VEGF levels (Kanda et al., 2015).

Interestingly, the widely adopted VEGF-A blocker Aflibercept is able to eliminate the pro-angiogenic effect of Gal-1, which appears to depend on the glycosylation state of Aflibercept (Kanda et al., 2015). Moreover, this dual effect has not been seen in similar studies using bevacizumab, a structurally different anti-VEGF. This observation may help to explain the variation in clinical efficacy 
seen between different anti-VEGF agents (Ridano et al., 2017). In clinical practice, a major challenge in anti-VEGF therapy is the large degree of variability seen in individual patient responses even when the same anti-VEGF agent is used; to date, attempts to explain this phenomenon through genetic studies have been largely unfruitful (Hagstrom et al., 2014). Given the evidence presented for the interaction between VEGF glycoconjugates and galectins, the glycosylation state of the retinal VEGF and its receptor may be an underappreciated factor in the variable responses observed with antiVEGF therapies (Wdowiak et al., 2018).

\section{Role of galectins in epithelial mesenchymal transformation}

Constitutive Gal-1 expression is important for the adhesion of the photoreceptor layer to the interphotoreceptor matrix; as evidenced by the observation that experimental injection of an antiGal-1 antibody induces retinal detachment and vacuolation (Uehara et al., 2001). Excessive levels of Gal-1 is correlated with RPE dedifferentiation and migration as reported in proliferative vitreoretinopathy (PVR), in which Gal-1 in epiretinal membranes show upregulation of this molecule as compared to controls (Eastlake et al., 2018). Furthermore, addition of exogenous Gal-1 to retinal membranes in culture inhibit the attachment and migration of PVR cells (Alge et al., 2006), whereas silencing the LGALS1 gene inhibited TGF- $\beta 1$ mediated EMT (Wu et al., 2019). Taken together, these data suggest that Gal-1 acts as an anchor for the RPE cell layer in the normal retina but is released in higher concentrations in the context of PVR pathogenesis, possibly in an effort to limit the aberrant migration of RPE cells.

Gal-3 inhibits RPE migration and attachment via the clustering of CD147 and integrin- $\beta 1$ (Priglinger et al., 2013). In vitro studies have demonstrated that these effects are mediated via activation of the extracellular signal-regulated kinase/mitogen-activated protein kinases (ERK/MAPK) pathway (AlgePriglinger et al., 2011), and that they are dependent on the activities of MGAT5 (Priglinger et al., 2016). Following modification by MGAT5, the N-glycans conjugated to EGF and TGF- $\beta$ receptors undergo cross-linking by Gal-3, thus stabilising the receptors and prolonging their expression (Partridge et al., 2004). The activity of Mgat5 appears to be a rate limiting step in cytokine signalling, as such, manipulation of this glycosylation enzyme as well as Gal-3 availability form attractive potential strategies in controlling aberrant EMT (Abu El-Asrar et al., 2011).

\section{Galectins in retinal development and regeneration}

During organ development, there is evidence that the spatial-temporal distribution of different members of the galectin family change over time; in addition, striking changes also occur in terms of their subcellular localisation (Kaltner et al., 2002). The zebrafish has proven to be a particularly informative model for studying embryogenesis, owing partly to the availability of its complete genome. A number of galectin-like molecules are expressed by the zebrafish (Vasta et al., 2004); in particular, Drgal1-L2, a teleost fish galectin structurally and functionally similar to mammalian Gal-1, was found to be expressed in the notochord during embryogenesis (Ahmed et al., 2004). Blocking Drgal1-L2 during zebrafish development resulted in skeletal and trunk defects (Ahmed et al., 2009). This work was also extended to the mammalian neural stem cells and olfactory system (Puche et al., 1996), where some studies demonstrate Gal-1 to stimulate stem cell proliferation (Sakaguchi et al., 2006), whilst other studies suggest a role for Gal-1 in axonal degeneration via the p75(NTR) neurotrophin receptor (Plachta et al., 2007). Gal-3 has also been shown to modulate gliogenesis within the mouse CNS via BMP signalling (Al-Dalahmah et al., 2020). Within the pig retina, Gal-3 has been isolated during development, exhibiting an increase in concentration during the first 6 months of life (Kim et al., 2009). In this case, the production of Gal-3 appears to originate from Müller cells, although its mechanism of action remains to be elucidated. 
It is well known that the teleost fish retina has the capability to endogenously regenerate following injury (Lenkowski and Raymond, 2014). This phenomenon has been ascribed to Müller glial cells being the source of progenitors which replenish the damaged photoreceptors and neurons (Bernardos et al., 2007). A study in teleost fish showed that the Drgal1-L2 protein is upregulated following retinal injury and that this coincides with retinal regeneration (Eastlake et al., 2017). Furthermore, knockdown of Drgal1-L2 diminished the regenerative process of rod photoreceptors within the zebrafish (Craig et al., 2010). In rodent models, Gal-3 is upregulated in Müller cells during retinal degeneration, whilst Gal-3 knockout mice exhibited attenuated retinal degeneration in a mouse model of cerebral hypoperfusion (Manouchehrian et al., 2015). Given the established role of Müller cells in the retinal regeneration of the teleost fish, the coinciding upregulation of galectins warrants further investigation in the pursuit of Müller cell based retinal therapies (Eastlake et al., 2019).

\section{Clinical applications of galectins and future directions}

As the functions of Galectins become better understood, there is a growing interest in developing specific inhibitors for the purposes of scientific exploration and potential therapeutic use. This has proven to be a challenging task, given the multivalent nature of galectins and their ability to selfassociate. In addition, it is difficult to design molecules to specifically inhibit the shallow groove in the CRD region of galectins, whilst achieving high specificity within a family of molecules which share highly conserved CRD amino acid sequences. Nevertheless, a variety of approaches to developing Gal-1 and -3 inhibitors appear to be yielding promising results (Blanchard et al., 2016).

Clinical applications for galectins are being pursued in areas which are thematically analogous to their functions as outlined in this review. Notably, a recent phase 2 clinical trial has been started for the use of TD139, an inhibitor of Gal-3, in the treatment of idiopathic pulmonary fibrosis (Chan et al., 2018); whilst GR-MD-02, another Gal-3 inhibitor, has been investigated in early clinical trials targeting psoriasis and fibrotic non-alcoholic steatohepatitis (Harrison et al., 2016; Ritchie et al., 2017); other studies in cancer and heart failure are also yielding promising results (Bartolazzi, 2018). Several commercial organisations have been actively pursuing therapeutic applications of galectin inhibitors in various clinical settings over the past few years (Blanchard et al., 2016). The outcome of these studies could provide crucial insights into the potential for targeting galectins during major disease processes.

From the insights described in this review, it is clear that galectins are versatile molecules that participate in a range of important biological systems. The seemingly disparate nature of their functions acts as a reminder that pathological processes such as inflammation, neovascularisation and fibrosis are most likely more interconnected than we currently appreciate. This is particularly true in ocular tissues where a major theme of recent research has been to divert diseases away from pathways which result in loss of function into pathways of repair and regeneration. As such, furthering our understanding of galectin-glycan interactions constitutes a crucial step in achieving this goal. 


\section{Acknowledgements}

This work was supported by Fight for Sight, Moorfields Eye Charity, and the NIHR Biomedical Research Centre at Moorfields Eye Hospital and UCL Institute of Ophthalmology, London, UK. 


\section{References}

Abreu, C.A., De Lima, S.V., Mendonca, H.R., Goulart, C.O., Martinez, A.M., 2017. Absence of galectin3 promotes neuroprotection in retinal ganglion cells after optic nerve injury. Histol Histopathol 32, 253-262.

Abu El-Asrar, A.M., Ahmad, A., Allegaert, E., Siddiquei, M.M., Alam, K., Gikandi, P.W., De Hertogh, G., Opdenakker, G., 2020. Galectin-1 studies in proliferative diabetic retinopathy. Acta Ophthalmol 98, e1-e12.

Abu El-Asrar, A.M., Missotten, L., Geboes, K., 2011. Expression of myofibroblast activation molecules in proliferative vitreoretinopathy epiretinal membranes. Acta Ophthalmol 89, e115-121.

Ahmad, N., Gabius, H.J., Andre, S., Kaltner, H., Sabesan, S., Roy, R., Liu, B., Macaluso, F., Brewer, C.F., 2004. Galectin-3 precipitates as a pentamer with synthetic multivalent carbohydrates and forms heterogeneous cross-linked complexes. J Biol Chem 279, 10841-10847.

Ahmed, H., Du, S.J., O'Leary, N., Vasta, G.R., 2004. Biochemical and molecular characterization of galectins from zebrafish (Danio rerio): notochord-specific expression of a prototype galectin during early embryogenesis. Glycobiology 14, 219-232.

Ahmed, H., Du, S.J., Vasta, G.R., 2009. Knockdown of a galectin-1-like protein in zebrafish (Danio rerio) causes defects in skeletal muscle development. Glycoconj J 26, 277-283.

Al-Dalahmah, O., Campos Soares, L., Nicholson, J., Draijer, S., Mundim, M., Lu, V.M., Sun, B., Tyler, T., Adorjan, I., O'Neill, E., Szele, F.G., 2020. Galectin-3 modulates postnatal subventricular zone gliogenesis. Glia 68, 435-450.

Alge-Priglinger, C.S., Andre, S., Schoeffl, H., Kampik, A., Strauss, R.W., Kernt, M., Gabius, H.J., Priglinger, S.G., 2011. Negative regulation of RPE cell attachment by carbohydrate-dependent cell surface binding of galectin-3 and inhibition of the ERK-MAPK pathway. Biochimie 93, 477-488.

Alge, C.S., Priglinger, S.G., Kook, D., Schmid, H., Haritoglou, C., Welge-Lussen, U., Kampik, A., 2006. Galectin-1 influences migration of retinal pigment epithelial cells. Invest Ophthalmol Vis Sci 47, 415426.

Amin, H.Z., Amin, L.Z., Wijaya, I.P., 2017. Galectin-3: a novel biomarker for the prognosis of heart failure. Clujul Med 90, 129-132.

Argueso, P., 2013. Glycobiology of the ocular surface: mucins and lectins. Jpn J Ophthalmol 57, 150155.

Argueso, P., Guzman-Aranguez, A., Mantelli, F., Cao, Z., Ricciuto, J., Panjwani, N., 2009. Association of cell surface mucins with galectin-3 contributes to the ocular surface epithelial barrier. J Biol Chem 284, 23037-23045.

Arthur, C.M., Baruffi, M.D., Cummings, R.D., Stowell, S.R., 2015. Evolving mechanistic insights into galectin functions. Methods Mol Biol 1207, 1-35.

Bartolazzi, A., 2018. Galectins in Cancer and Translational Medicine: From Bench to Bedside. Int J Mol Sci 19.

Belmares, R., Raychaudhuri, U., Maansson, S., Clark, A.F., 2018. Histological investigation of human glaucomatous eyes: Extracellular fibrotic changes and galectin 3 expression in the trabecular meshwork and optic nerve head. Clin Anat 31, 1031-1049.

Bernardos, R.L., Barthel, L.K., Meyers, J.R., Raymond, P.A., 2007. Late-stage neuronal progenitors in the retina are radial Muller glia that function as retinal stem cells. J Neurosci 27, 7028-7040.

Blanchard, H., Bum-Erdene, K., Bohari, M.H., Yu, X., 2016. Galectin-1 inhibitors and their potential therapeutic applications: a patent review. Expert Opin Ther Pat 26, 537-554.

Blazevits, O., Mideksa, Y.G., Solman, M., Ligabue, A., Ariotti, N., Nakhaeizadeh, H., Fansa, E.K., Papageorgiou, A.C., Wittinghofer, A., Ahmadian, M.R., Abankwa, D., 2016. Galectin-1 dimers can scaffold Raf-effectors to increase H-ras nanoclustering. Sci Rep 6, 24165.

Boscher, C., Dennis, J.W., Nabi, I.R., 2011. Glycosylation, galectins and cellular signaling. Curr Opin Cell Biol 23, 383-392.

Burguillos, M.A., Svensson, M., Schulte, T., Boza-Serrano, A., Garcia-Quintanilla, A., Kavanagh, E., Santiago, M., Viceconte, N., Oliva-Martin, M.J., Osman, A.M., Salomonsson, E., Amar, L., Persson, A., 
Blomgren, K., Achour, A., Englund, E., Leffler, H., Venero, J.L., Joseph, B., Deierborg, T., 2015. Microglia-Secreted Galectin-3 Acts as a Toll-like Receptor 4 Ligand and Contributes to Microglial Activation. Cell Rep 10, 1626-1638.

Caberoy, N.B., Alvarado, G., Bigcas, J.L., Li, W., 2012. Galectin-3 is a new MerTK-specific eat-me signal. J Cell Physiol 227, 401-407.

Camby, I., Le Mercier, M., Lefranc, F., Kiss, R., 2006. Galectin-1: a small protein with major functions. Glycobiology 16, 137R-157R.

Cao, Z., Said, N., Amin, S., Wu, H.K., Bruce, A., Garate, M., Hsu, D.K., Kuwabara, I., Liu, F.T., Panjwani, N., 2002a. Galectins-3 and -7, but not galectin-1, play a role in re-epithelialization of wounds. J Biol Chem 277, 42299-42305.

Cao, Z., Said, N., Wu, H.K., Kuwabara, I., Liu, F.T., Panjwani, N., 2003. Galectin-7 as a potential mediator of corneal epithelial cell migration. Arch Ophthalmol 121, 82-86.

Cao, Z., Wu, H.K., Bruce, A., Wollenberg, K., Panjwani, N., 2002b. Detection of differentially expressed genes in healing mouse corneas, using cDNA microarrays. Invest Ophthalmol Vis Sci 43, 2897-2904.

Chan, Y.C., Lin, H.Y., Tu, Z., Kuo, Y.H., Hsu, S.D., Lin, C.H., 2018. Dissecting the Structure-Activity Relationship of Galectin-Ligand Interactions. Int J Mol Sci 19.

Chatterjee, A., Villarreal, G., Jr., Rhee, D.J., 2014. Matricellular proteins in the trabecular meshwork: review and update. J Ocul Pharmacol Ther 30, 447-463.

Chen, W.S., Cao, Z., Sugaya, S., Lopez, M.J., Sendra, V.G., Laver, N., Leffler, H., Nilsson, U.J., Fu, J., Song, J., Xia, L., Hamrah, P., Panjwani, N., 2016. Pathological lymphangiogenesis is modulated by galectin-8-dependent crosstalk between podoplanin and integrin-associated VEGFR-3. Nat Commun 7, 11302.

Chen, W.S., Cao, Z., Truong, L., Sugaya, S., Panjwani, N., 2015. Fingerprinting of galectins in normal, P. aeruginosa-infected, and chemically burned mouse corneas. Invest Ophthalmol Vis Sci 56, 515525.

Chen, X.L., Nam, J.O., Jean, C., Lawson, C., Walsh, C.T., Goka, E., Lim, S.T., Tomar, A., Tancioni, I., Uryu, S., Guan, J.L., Acevedo, L.M., Weis, S.M., Cheresh, D.A., Schlaepfer, D.D., 2012. VEGF-induced vascular permeability is mediated by FAK. Dev Cell 22, 146-157.

Chiariotti, L., Salvatore, P., Frunzio, R., Bruni, C.B., 2002. Galectin genes: regulation of expression. Glycoconj J 19, 441-449.

Chou, F.C., Chen, H.Y., Kuo, C.C., Sytwu, H.K., 2018. Role of Galectins in Tumors and in Clinical Immunotherapy. Int J Mol Sci 19.

Craig, S.E., Thummel, R., Ahmed, H., Vasta, G.R., Hyde, D.R., Hitchcock, P.F., 2010. The zebrafish galectin Drgal1-12 is expressed by proliferating Muller glia and photoreceptor progenitors and regulates the regeneration of rod photoreceptors. Invest Ophthalmol Vis Sci 51, 3244-3252.

Cruzat, A., Gonzalez-Andrades, M., Mauris, J., AbuSamra, D.B., Chidambaram, P., Kenyon, K.R., Chodosh, J., Dohlman, C.H., Argueso, P., 2018. Colocalization of Galectin-3 With CD147 Is Associated With Increased Gelatinolytic Activity in Ulcerating Human Corneas. Invest Ophthalmol Vis Sci 59, 223-230.

Cummings, R.D., 2009. The repertoire of glycan determinants in the human glycome. Mol Biosyst 5 , 1087-1104.

D'Haene, N., Sauvage, S., Maris, C., Adanja, I., Le Mercier, M., Decaestecker, C., Baum, L., Salmon, I., 2013. VEGFR1 and VEGFR2 involvement in extracellular galectin-1- and galectin-3-induced angiogenesis. PLoS One 8, e67029.

Diskin, S., Cao, Z., Leffler, H., Panjwani, N., 2009. The role of integrin glycosylation in galectin-8mediated trabecular meshwork cell adhesion and spreading. Glycobiology 19, 29-37.

Eastlake, K., Heywood, W.E., Banerjee, P., Bliss, E., Mills, K., Khaw, P.T., Charteris, D., Limb, G.A., 2018. Comparative proteomic analysis of normal and gliotic PVR retina and contribution of Muller glia to this profile. Exp Eye Res 177, 197-207. 
Eastlake, K., Heywood, W.E., Tracey-White, D., Aquino, E., Bliss, E., Vasta, G.R., Mills, K., Khaw, P.T., Moosajee, M., Limb, G.A., 2017. Comparison of proteomic profiles in the zebrafish retina during experimental degeneration and regeneration. Sci Rep 7, 44601.

Eastlake, K., Luis, J., Limb, G.A., 2019. Potential of Muller Glia for Retina Neuroprotection. Curr Eye Res, 1-10.

Fajka-Boja, R., Urban, V.S., Szebeni, G.J., Czibula, A., Blasko, A., Kriston-Pal, E., Makra, I., Hornung, A., Szabo, E., Uher, F., Than, N.G., Monostori, E., 2016. Galectin-1 is a local but not systemic immunomodulatory factor in mesenchymal stromal cells. Cytotherapy 18, 360-370.

Fautsch, M.P., Silva, A.O., Johnson, D.H., 2003. Carbohydrate binding proteins galectin-1 and galectin-3 in human trabecular meshwork. Exp Eye Res 77, 11-16.

Ferrara, N., Adamis, A.P., 2016. Ten years of anti-vascular endothelial growth factor therapy. Nat Rev Drug Discov 15, 385-403.

Fini, M.E., Bauskar, A., Jeong, S., Wilson, M.R., 2016. Clusterin in the eye: An old dog with new tricks at the ocular surface. Exp Eye Res 147, 57-71.

Fukushima, A., Sumi, T., Fukuda, K., Kumagai, N., Nishida, T., Okumura, K., Akiba, H., Yagita, H., Ueno, H., 2008. Roles of galectin-9 in the development of experimental allergic conjunctivitis in mice. Int Arch Allergy Immunol 146, 36-43.

Gabius, H.J., 2018. The sugar code: Why glycans are so important. Biosystems 164, 102-111.

Gabius, H.J., Siebert, H.C., Andre, S., Jimenez-Barbero, J., Rudiger, H., 2004. Chemical biology of the sugar code. Chembiochem 5, 740-764.

Gonen, T., Donaldson, P., Kistler, J., 2000. Galectin-3 is associated with the plasma membrane of lens fiber cells. Invest Ophthalmol Vis Sci 41, 199-203.

Guzman-Aranguez, A., Argueso, P., 2010. Structure and biological roles of mucin-type O-glycans at the ocular surface. Ocul Surf 8, 8-17.

Hagstrom, S.A., Ying, G.S., Pauer, G.J., Sturgill-Short, G.M., Huang, J., Maguire, M.G., Martin, D.F., Comparison of Age-Related Macular Degeneration Treatments Trials Research, G., 2014. VEGFA and VEGFR2 gene polymorphisms and response to anti-vascular endothelial growth factor therapy: comparison of age-related macular degeneration treatments trials (CATT). JAMA Ophthalmol 132, 521-527.

Harrison, S.A., Marri, S.R., Chalasani, N., Kohli, R., Aronstein, W., Thompson, G.A., Irish, W., Miles, M.V., Xanthakos, S.A., Lawitz, E., Noureddin, M., Schiano, T.D., Siddiqui, M., Sanyal, A., Neuschwander-Tetri, B.A., Traber, P.G., 2016. Randomised clinical study: GR-MD-02, a galectin-3 inhibitor, vs. placebo in patients having non-alcoholic steatohepatitis with advanced fibrosis. Aliment Pharmacol Ther 44, 1183-1198.

He, J., Baum, L.G., 2006. Galectin interactions with extracellular matrix and effects on cellular function. Methods Enzymol 417, 247-256.

Henderson, N.C., Mackinnon, A.C., Farnworth, S.L., Poirier, F., Russo, F.P., Iredale, J.P., Haslett, C., Simpson, K.J., Sethi, T., 2006. Galectin-3 regulates myofibroblast activation and hepatic fibrosis. Proc Natl Acad Sci U S A 103, 5060-5065.

Hirose, I., Kanda, A., Noda, K., Ishida, S., 2019. Glucocorticoid receptor inhibits Muller glial galectin-1 expression via DUSP1-dependent and -independent deactivation of AP-1 signalling. J Cell Mol Med 23, 6785-6796.

Hrdlickova-Cela, E., Plzak, J., Smetana, K., Jr., Melkova, Z., Kaltner, H., Filipec, M., Liu, F.T., Gabius, H.J., 2001. Detection of galectin-3 in tear fluid at disease states and immunohistochemical and lectin histochemical analysis in human corneal and conjunctival epithelium. Br J Ophthalmol 85, 13361340.

Inohara, H., Akahani, S., Raz, A., 1998. Galectin-3 stimulates cell proliferation. Exp Cell Res 245, 294302.

Ishida, K., Panjwani, N., Cao, Z., Streilein, J.W., 2003. Participation of pigment epithelium in ocular immune privilege. 3. Epithelia cultured from iris, ciliary body, and retina suppress T-cell activation by partially non-overlapping mechanisms. Ocul Immunol Inflamm 11, 91-105. 
Johannes, L., Jacob, R., Leffler, H., 2018. Galectins at a glance. J Cell Sci 131.

Juszczynski, P., Ouyang, J., Monti, S., Rodig, S.J., Takeyama, K., Abramson, J., Chen, W., Kutok, J.L., Rabinovich, G.A., Shipp, M.A., 2007. The AP1-dependent secretion of galectin-1 by Reed Sternberg cells fosters immune privilege in classical Hodgkin lymphoma. Proc Natl Acad Sci U S A 104, 1313413139.

Kaltner, H., Seyrek, K., Heck, A., Sinowatz, F., Gabius, H.J., 2002. Galectin-1 and galectin-3 in fetal development of bovine respiratory and digestive tracts. Comparison of cell type-specific expression profiles and subcellular localization. Cell Tissue Res 307, 35-46.

Kamili, N.A., Arthur, C.M., Gerner-Smidt, C., Tafesse, E., Blenda, A., Dias-Baruffi, M., Stowell, S.R., 2016. Key regulators of galectin-glycan interactions. Proteomics 16, 3111-3125.

Kanda, A., Dong, Y., Noda, K., Saito, W., Ishida, S., 2017. Advanced glycation endproducts link inflammatory cues to upregulation of galectin-1 in diabetic retinopathy. Sci Rep 7, 16168.

Kanda, A., Noda, K., Saito, W., Ishida, S., 2015. Aflibercept Traps Galectin-1, an Angiogenic Factor Associated with Diabetic Retinopathy. Sci Rep 5, 17946.

Kang, M.H., Oh, D.J., Kang, J.H., Rhee, D.J., 2013. Regulation of SPARC by transforming growth factor beta2 in human trabecular meshwork. Invest Ophthalmol Vis Sci 54, 2523-2532.

Karlsson, A., Christenson, K., Matlak, M., Bjorstad, A., Brown, K.L., Telemo, E., Salomonsson, E., Leffler, H., Bylund, J., 2009. Galectin-3 functions as an opsonin and enhances the macrophage clearance of apoptotic neutrophils. Glycobiology 19, 16-20.

Kim, J., Moon, C., Ahn, M., Joo, H.G., Jin, J.K., Shin, T., 2009. Immunohistochemical localization of galectin-3 in the pig retina during postnatal development. Mol Vis 15, 1971-1976.

Laine, R.A., 1994. A calculation of all possible oligosaccharide isomers both branched and linear yields $1.05 \times 10$ (12) structures for a reducing hexasaccharide: the Isomer Barrier to development of single-method saccharide sequencing or synthesis systems. Glycobiology 4, 759-767.

Lakshminarayan, R., Wunder, C., Becken, U., Howes, M.T., Benzing, C., Arumugam, S., Sales, S., Ariotti, N., Chambon, V., Lamaze, C., Loew, D., Shevchenko, A., Gaus, K., Parton, R.G., Johannes, L., 2014. Galectin-3 drives glycosphingolipid-dependent biogenesis of clathrin-independent carriers. Nat Cell Biol 16, 595-606.

Lee, H.J., Kim, J.H., Hong, S., Hwang, I., Park, S.J., Kim, T.I., Kim, W.H., Yu, J.W., Kim, S.W., Cheon, J.H., 2019. Proteomics-based functional studies reveal that galectin-3 plays a protective role in the pathogenesis of intestinal Behcet's disease. Sci Rep 9, 11716.

Lee, Y.J., Kang, S.W., Song, J.K., Park, J.J., Bae, Y.D., Lee, E.Y., Lee, E.B., Song, Y.W., 2007. Serum galectin-3 and galectin-3 binding protein levels in Behcet's disease and their association with disease activity. Clin Exp Rheumatol 25, S41-45.

Leffler, H., Carlsson, S., Hedlund, M., Qian, Y., Poirier, F., 2002. Introduction to galectins. Glycoconj J $19,433-440$.

Lenkowski, J.R., Raymond, P.A., 2014. Muller glia: Stem cells for generation and regeneration of retinal neurons in teleost fish. Prog Retin Eye Res 40, 94-123.

Li, L.C., Li, J., Gao, J., 2014. Functions of galectin-3 and its role in fibrotic diseases. J Pharmacol Exp Ther 351, 336-343.

Luo, L.H., Li, D.M., Wang, Y.L., Wang, K., Gao, L.X., Li, S., Yang, J.G., Li, C.L., Feng, W., Guo, H., 2017. Tim3/galectin-9 alleviates the inflammation of TAO patients via suppressing Akt/NF-kB signaling pathway. Biochem Biophys Res Commun 491, 966-972.

Mackinnon, A.C., Gibbons, M.A., Farnworth, S.L., Leffler, H., Nilsson, U.J., Delaine, T., Simpson, A.J., Forbes, S.J., Hirani, N., Gauldie, J., Sethi, T., 2012. Regulation of transforming growth factor-beta1driven lung fibrosis by galectin-3. Am J Respir Crit Care Med 185, 537-546.

Manouchehrian, O., Arner, K., Deierborg, T., Taylor, L., 2015. Who let the dogs out?: detrimental role of Galectin-3 in hypoperfusion-induced retinal degeneration. J Neuroinflammation 12, 92.

Markowska, A.I., Jefferies, K.C., Panjwani, N., 2011. Galectin-3 protein modulates cell surface expression and activation of vascular endothelial growth factor receptor 2 in human endothelial cells. J Biol Chem 286, 29913-29921. 
Markowska, A.I., Liu, F.T., Panjwani, N., 2010. Galectin-3 is an important mediator of VEGF- and bFGF-mediated angiogenic response. J Exp Med 207, 1981-1993.

Mauris, J., Woodward, A.M., Cao, Z., Panjwani, N., Argueso, P., 2014. Molecular basis for MMP9 induction and disruption of epithelial cell-cell contacts by galectin-3. J Cell Sci 127, 3141-3148.

Melo, F.H., Butera, D., Junqueira Mde, S., Hsu, D.K., da Silva, A.M., Liu, F.T., Santos, M.F., Chammas, R., 2011. The promigratory activity of the matricellular protein galectin-3 depends on the activation of PI-3 kinase. PLoS One 6, e29313.

Mochizuki, M., Sugita, S., Kamoi, K., 2013. Immunological homeostasis of the eye. Prog Retin Eye Res 33, 10-27.

Moiseeva, E.P., Williams, B., Samani, N.J., 2003. Galectin 1 inhibits incorporation of vitronectin and chondroitin sulfate $B$ into the extracellular matrix of human vascular smooth muscle cells. Biochim Biophys Acta 1619, 125-132.

Nagae, M., Nishi, N., Murata, T., Usui, T., Nakamura, T., Wakatsuki, S., Kato, R., 2009. Structural analysis of the recognition mechanism of poly- $\mathrm{N}$-acetyllactosamine by the human galectin- $9 \mathrm{~N}$ terminal carbohydrate recognition domain. Glycobiology 19, 112-117.

Nielsen, M.I., Stegmayr, J., Grant, O.C., Yang, Z., Nilsson, U.J., Boos, I., Carlsson, M.C., Woods, R.J., Unverzagt, C., Leffler, H., Wandall, H.H., 2018. Galectin binding to cells and glycoproteins with genetically modified glycosylation reveals galectin-glycan specificities in a natural context. J Biol Chem 293, 20249-20262.

Nishi, Y., Sano, H., Kawashima, T., Okada, T., Kuroda, T., Kikkawa, K., Kawashima, S., Tanabe, M., Goto, T., Matsuzawa, Y., Matsumura, R., Tomioka, H., Liu, F.T., Shirai, K., 2007. Role of galectin-3 in human pulmonary fibrosis. Allergol Int 56, 57-65.

Obermann, J., Priglinger, C.S., Merl-Pham, J., Geerlof, A., Priglinger, S., Gotz, M., Hauck, S.M., 2017. Proteome-wide Identification of Glycosylation-dependent Interactors of Galectin-1 and Galectin-3 on Mesenchymal Retinal Pigment Epithelial (RPE) Cells. Mol Cell Proteomics 16, 1528-1546.

Partridge, E.A., Le Roy, C., Di Guglielmo, G.M., Pawling, J., Cheung, P., Granovsky, M., Nabi, I.R., Wrana, J.L., Dennis, J.W., 2004. Regulation of cytokine receptors by Golgi N-glycan processing and endocytosis. Science 306, 120-124.

Perillo, N.L., Pace, K.E., Seilhamer, J.J., Baum, L.G., 1995. Apoptosis of T cells mediated by galectin-1. Nature 378, 736-739.

Plachta, N., Annaheim, C., Bissiere, S., Lin, S., Ruegg, M., Hoving, S., Muller, D., Poirier, F., Bibel, M., Barde, Y.A., 2007. Identification of a lectin causing the degeneration of neuronal processes using engineered embryonic stem cells. Nat Neurosci 10, 712-719.

Popa, S.J., Stewart, S.E., Moreau, K., 2018. Unconventional secretion of annexins and galectins. Semin Cell Dev Biol 83, 42-50.

Priglinger, C.S., Obermann, J., Szober, C.M., Merl-Pham, J., Ohmayer, U., Behler, J., Gruhn, F., Kreutzer, T.C., Wertheimer, C., Geerlof, A., Priglinger, S.G., Hauck, S.M., 2016. Epithelial-toMesenchymal Transition of RPE Cells In Vitro Confers Increased beta1,6-N-Glycosylation and Increased Susceptibility to Galectin-3 Binding. PLoS One 11, e0146887.

Priglinger, C.S., Szober, C.M., Priglinger, S.G., Merl, J., Euler, K.N., Kernt, M., Gondi, G., Behler, J., Geerlof, A., Kampik, A., Ueffing, M., Hauck, S.M., 2013. Galectin-3 induces clustering of CD147 and integrin-beta1 transmembrane glycoprotein receptors on the RPE cell surface. PLoS One 8, e70011. Puche, A.C., Poirier, F., Hair, M., Bartlett, P.F., Key, B., 1996. Role of galectin-1 in the developing mouse olfactory system. Dev Biol 179, 274-287.

Rhee, D.J., Fariss, R.N., Brekken, R., Sage, E.H., Russell, P., 2003. The matricellular protein SPARC is expressed in human trabecular meshwork. Exp Eye Res 77, 601-607.

Rhee, D.J., Haddadin, R.I., Kang, M.H., Oh, D.J., 2009. Matricellular proteins in the trabecular meshwork. Exp Eye Res 88, 694-703.

Ridano, M.E., Subirada, P.V., Paz, M.C., Lorenc, V.E., Stupirski, J.C., Gramajo, A.L., Luna, J.D., Croci, D.O., Rabinovich, G.A., Sanchez, M.C., 2017. Galectin-1 expression imprints a neurovascular 
phenotype in proliferative retinopathies and delineates responses to anti-VEGF. Oncotarget 8, 32505-32522.

Ritchie, S., Neal, D., Shlevin, H., Allgood, A., Traber, P., 2017. A phase 2a, open-label pilot study of the galectin-3 inhibitor GR-MD-02 for the treatment of moderate-to-severe plaque psoriasis. J Am Acad Dermatol 77, 753-755.

Romero, M.D., Muino, J.C., Bianco, G.A., Ferrero, M., Juarez, C.P., Luna, J.D., Rabinovich, G.A., 2006. Circulating anti-galectin- 1 antibodies are associated with the severity of ocular disease in autoimmune and infectious uveitis. Invest Ophthalmol Vis Sci 47, 1550-1556.

Sakaguchi, M., Shingo, T., Shimazaki, T., Okano, H.J., Shiwa, M., Ishibashi, S., Oguro, H., Ninomiya, M., Kadoya, T., Horie, H., Shibuya, A., Mizusawa, H., Poirier, F., Nakauchi, H., Sawamoto, K., Okano, H., 2006. A carbohydrate-binding protein, Galectin-1, promotes proliferation of adult neural stem cells. Proc Natl Acad Sci U S A 103, 7112-7117.

Sampson, J.F., Hasegawa, E., Mulki, L., Suryawanshi, A., Jiang, S., Chen, W.S., Rabinovich, G.A., Connor, K.M., Panjwani, N., 2015. Galectin-8 Ameliorates Murine Autoimmune Ocular Pathology and Promotes a Regulatory T Cell Response. PLoS One 10, e0130772.

Sampson, J.F., Suryawanshi, A., Chen, W.S., Rabinovich, G.A., Panjwani, N., 2016. Galectin-8 promotes regulatory T-cell differentiation by modulating IL-2 and TGFbeta signaling. Immunol Cell Biol 94, 213-219.

Saravanan, C., Liu, F.T., Gipson, I.K., Panjwani, N., 2009. Galectin-3 promotes lamellipodia formation in epithelial cells by interacting with complex N-glycans on alpha3beta1 integrin. J Cell Sci 122, 36843693.

Sehrawat, S., Suryawanshi, A., Hirashima, M., Rouse, B.T., 2009. Role of Tim-3/galectin-9 inhibitory interaction in viral-induced immunopathology: shifting the balance toward regulators. J Immunol 182, 3191-3201.

Sharma, U.C., Pokharel, S., van Brakel, T.J., van Berlo, J.H., Cleutjens, J.P., Schroen, B., Andre, S., Crijns, H.J., Gabius, H.J., Maessen, J., Pinto, Y.M., 2004. Galectin-3 marks activated macrophages in failure-prone hypertrophied hearts and contributes to cardiac dysfunction. Circulation 110, 31213128.

Shen, H., Wang, J., Min, J., Xi, W., Gao, Y., Yin, L., Yu, Y., Liu, K., Xiao, J., Zhang, Y.F., Wang, Z.N., 2018. Activation of TGF-beta1/alpha-SMA/Col I Profibrotic Pathway in Fibroblasts by Galectin-3 Contributes to Atrial Fibrosis in Experimental Models and Patients. Cell Physiol Biochem 47, 851-863. Shimmura-Tomita, M., Wang, M., Taniguchi, H., Akiba, H., Yagita, H., Hori, J., 2013. Galectin-9mediated protection from allo-specific $\mathrm{T}$ cells as a mechanism of immune privilege of corneal allografts. PLoS One 8, e63620.

Siew, J.J., Chen, H.M., Chen, H.Y., Chen, H.L., Chen, C.M., Soong, B.W., Wu, Y.R., Chang, C.P., Chan, Y.C., Lin, C.H., Liu, F.T., Chern, Y., 2019. Galectin-3 is required for the microglia-mediated brain inflammation in a model of Huntington's disease. Nat Commun 10, 3473.

Soria, J., Acera, A., Duran, J.A., Boto-de-Los-Bueis, A., Del-Hierro-Zarzuelo, A., Gonzalez, N., Reigada, R., Suarez, T., 2018. The analysis of human conjunctival epithelium proteome in ocular surface diseases using impression cytology and 2D-DIGE. Exp Eye Res 167, 31-43.

Starossom, S.C., Mascanfroni, I.D., Imitola, J., Cao, L., Raddassi, K., Hernandez, S.F., Bassil, R., Croci, D.O., Cerliani, J.P., Delacour, D., Wang, Y., Elyaman, W., Khoury, S.J., Rabinovich, G.A., 2012. Galectin-1 deactivates classically activated microglia and protects from inflammation-induced neurodegeneration. Immunity 37, 249-263.

Stowell, S.R., Arthur, C.M., Mehta, P., Slanina, K.A., Blixt, O., Leffler, H., Smith, D.F., Cummings, R.D., 2008. Galectin-1, -2 , and -3 exhibit differential recognition of sialylated glycans and blood group antigens. J Biol Chem 283, 10109-10123.

Sugaya, S., Chen, W.S., Cao, Z., Kenyon, K.R., Yamaguchi, T., Omoto, M., Hamrah, P., Panjwani, N., 2015. Comparison of galectin expression signatures in rejected and accepted murine corneal allografts. Cornea 34, 675-681. 
Suryawanshi, A., Cao, Z., Thitiprasert, T., Zaidi, T.S., Panjwani, N., 2013. Galectin-1-mediated suppression of Pseudomonas aeruginosa-induced corneal immunopathology. J Immunol 190, 63976409.

Suthahar, N., Meijers, W.C., Sillje, H.H.W., Ho, J.E., Liu, F.T., de Boer, R.A., 2018. Galectin-3 Activation and Inhibition in Heart Failure and Cardiovascular Disease: An Update. Theranostics 8, 593-609. Taniguchi, T., Woodward, A.M., Magnelli, P., McColgan, N.M., Lehoux, S., Jacobo, S.M.P., Mauris, J., Argueso, P., 2017. N-Glycosylation affects the stability and barrier function of the MUC16 mucin. J Biol Chem 292, 11079-11090.

Thiemann, S., Baum, L.G., 2016. Galectins and Immune Responses-Just How Do They Do Those Things They Do? Annu Rev Immunol 34, 243-264.

Toscano, M.A., Commodaro, A.G., Ilarregui, J.M., Bianco, G.A., Liberman, A., Serra, H.M., Hirabayashi, J., Rizzo, L.V., Rabinovich, G.A., 2006. Galectin-1 suppresses autoimmune retinal disease by promoting concomitant Th2- and T regulatory-mediated anti-inflammatory responses. J Immunol 176, 6323-6332.

Tripathi, R.C., Li, J., Chan, W.F., Tripathi, B.J., 1994. Aqueous humor in glaucomatous eyes contains an increased level of TGF-beta 2. Exp Eye Res 59, 723-727.

Uchino, Y., 2018. The Ocular Surface Glycocalyx and its Alteration in Dry Eye Disease: A Review. Invest Ophthalmol Vis Sci 59, DES157-DES162.

Uchino, Y., Woodward, A.M., Mauris, J., Peterson, K., Verma, P., Nilsson, U.J., Rajaiya, J., Argueso, P., 2018. Galectin-3 is an amplifier of the interleukin-1beta-mediated inflammatory response in corneal keratinocytes. Immunology 154, 490-499.

Uehara, F., Ohba, N., Ozawa, M., 2001. Isolation and characterization of galectins in the mammalian retina. Invest Ophthalmol Vis Sci 42, 2164-2172.

van der Leij, J., van den Berg, A., Blokzijl, T., Harms, G., van Goor, H., Zwiers, P., van Weeghel, R., Poppema, S., Visser, L., 2004. Dimeric galectin-1 induces IL-10 production in T-lymphocytes: an important tool in the regulation of the immune response. J Pathol 204, 511-518.

Varki, A., 1993. Biological roles of oligosaccharides: all of the theories are correct. Glycobiology 3, 97130.

Vasta, G.R., Ahmed, H., Du, S., Henrikson, D., 2004. Galectins in teleost fish: Zebrafish (Danio rerio) as a model species to address their biological roles in development and innate immunity. Glycoconj J 21, 503-521.

Wdowiak, K., Francuz, T., Gallego-Colon, E., Ruiz-Agamez, N., Kubeczko, M., Grochola, I., Wojnar, J., 2018. Galectin Targeted Therapy in Oncology: Current Knowledge and Perspectives. Int J Mol Sci 19. Weinreb, R.N., Aung, T., Medeiros, F.A., 2014. The pathophysiology and treatment of glaucoma: a review. JAMA 311, 1901-1911.

Woodward, A.M., Mauris, J., Argueso, P., 2013. Binding of transmembrane mucins to galectin-3 limits herpesvirus 1 infection of human corneal keratinocytes. J Virol 87, 5841-5847.

Wu, D., Kanda, A., Liu, Y., Kase, S., Noda, K., Ishida, S., 2019. Galectin-1 promotes choroidal neovascularization and subretinal fibrosis mediated via epithelial-mesenchymal transition. FASEB J 33, 2498-2513.

Yang, N., Zhang, W., He, T., Xing, Y., 2017. Suppression of Retinal Neovascularization by Inhibition of Galectin-1 in a Murine Model of Oxygen-Induced Retinopathy. J Ophthalmol 2017, 5053035.

Yang, R.Y., Hsu, D.K., Liu, F.T., 1996. Expression of galectin-3 modulates T-cell growth and apoptosis. Proc Natl Acad Sci U S A 93, 6737-6742.

Zanon Cde, F., Sonehara, N.M., Girol, A.P., Gil, C.D., Oliani, S.M., 2015. Protective effects of the galectin-1 protein on in vivo and in vitro models of ocular inflammation. Mol Vis 21, 1036-1050. Zhong, X., Qian, X., Chen, G., Song, X., 2019. The role of galectin-3 in heart failure and cardiovascular disease. Clin Exp Pharmacol Physiol 46, 197-203. 